\title{
INFLUÊNCIA DAS VARIÁVEIS DE PROCESSO NA ALCOÓliSE ENZIMÁTICA DE ÓLEO DE MAMONA ${ }^{1}$
}

\author{
D. OLIVEIRA ${ }^{2 *}$, J.V. OLIVEIRA ${ }^{2}$, C. FACCIO ${ }^{2}$, S. MENONCIN² ${ }^{2}$ C. AMROGINSKI ${ }^{2}$
}

\section{RESUMO}

O potencial de aplicação de lipases em processos biotecnológicos para a modificação de óleos e gorduras tem sido objeto de grande interesse nos meios científico, econômico e industrial nos últimos anos. Além da atividade de hidrólise de ésteres, as lipases podem catalisar uma grande variedade de reações de esterificação, transesterificação e poliesterificação. A transesterificação inclui acidólise, interesterificação e alcoólise. Neste trabalho reações de alcoólise de óleo de mamona para produção de ésteres de ácidos graxos foram estudadas devido a sua importância na obtenção de, por exemplo, agentes de antifricção, emulsificantes, intermediários para produzir uma numerosa quantidade de oleoquímicos e combustível alternativo ao diesel e/ou aditivo ao diesel de petróleo (biodiesel). Neste contexto, foi estudada a etanólise enzimática de óleo de mamona com lipase comercial (Lipozyme IM) usando n-hexano como solvente. Os experimentos foram realizados variando a temperatura, as concentrações de água e enzima no meio reacional e a razão molar óleoetanol, de acordo com um planejamento de experimentos pré-estabelecidos. Um modelo empírico foi utilizado para avaliar a influência das variáveis de processo no rendimento e, desta forma, as condições de operação que maximizam a produção de ésteres foram estabelecidas para a enzima utilizada.

Palavras-chave: lipase; alcoólise; biodiesel; óleo de mamona.

\section{SUMMARY}

EVALUATION OF THE INFLUENCE OF PROCESS VARIABLES ON ENZIMATIC ALCOHOLYSIS OF CASTOR OIL. The use of lipases as biocatalysts in ester synthesis has been the object of growing interest. In addition to glycerol ester hydrolysis, lipases can catalyze a wide variety of esterification, transesterification and polyesterification reactions. The transesterification includes acidolysis, interesterification and alcoholysis. We consider in this report the application of lipases in the alcoholysis of brazilian vegetable oil in the production of fatty acid esters due to its importance as, for example, antifriction agents, food preservatives, emulsifiers and intermediates to produce a number of oleochemicals and fuel alternatives (biodiesel). In this work, enzymatic alcoholysis of castor bean oil with an immobilized lipase (Lipozyme IM) was accomplished using n-hexane as solvent. In order to maximize the esters production a Taguchi design was adopted varying temperature, water and enzyme concentrations in the reaction media and the oil:ethanol molar ratio. The reactions were monitorated by determining the glycerol production. An empirical model was built to evaluate the influence of the process variables on the conversion and afterwards the operating conditions that maximize esters production were established. Keywords: lipases; alcoholysis; biodiesel; castor bean oil.

\section{1 - INTRODUÇÃO}

Lipases têm sido extensivamente usadas em tecnologia de triglicerídeos, sendo aplicadas, principalmente, na biotransformação de óleos e gorduras. Entre os processos mais promissores para a modificação de lipídios estão as reações de hidrólise, sintese de ésteres e interesterificação destes materiais na presença de lipases. A reação de hidrólise envolve ataque na ligação éster do triglicerídeo na presença de moléculas de água para produzir glicerol e ácidos graxos. A alta especificidade das lipases com relação ao tipo e à posição estereoespecífica do resíduo de ácido graxo têm sugerido um grande número de aplicações na área de alimentos. Flavorizantes para uso em alimentos destinados ao consumo humano e animal têm sido obtidos pela hidrólise parcial de triglicerídeos [9]. A reação de esterificação entre álcoois polihídricos e ácidos graxos livres é, em sua essência, a reação inversa da hidrólise do glicerídeo correspondente. Exemplos de produtos quí-

\footnotetext{
Recebido para publicação em 05/03/2002. Aceito para publicação em 25/03/2004 (000811).

2. Departamento de Ciências Agrárias, Curso de Engenharia de Alimentos URI - Campus de Erechim - Av. Sete de Setembro, 1621 CEP 99700000, Erechim/RS /Brasil. Telefone: (Oxx54) 520-9000. E-mail: odebora@uricer.edu.br

* A quem a correspondência deve ser enviada.
}

micos de alto valor, obtidos pelo uso de lipases para a esterificação, incluem a síntese de ésteres de ácido oléico com álcoois alifáticos primários e secundários e álcoois terpênicos e a produção de ésteres dos álcoois geraniol e mentol com ácido butírico e ácido láurico, respectivamente. O termo interesterificação refere-se à troca de radicais acil entre um éster e um ácido (acidólise), um éster e um álcool (alcoólise) ou um éster e outro éster (transesterificação). Nessas reações o triglicerídeo reage com um ácido graxo, um álcool ou outro éster, resultando em um rearranjo dos grupos de ácidos graxos do triglicerídeo de forma a produzir-se um novo triglicerídeo. O rearranjo é o resultado de reações concorrentes de hidrólise e esterificação.

Ésteres obtidos a partir de álcoois e ácidos graxos possuem muitas aplicações e, aqueles obtidos a partir de ácidos de cadeia longa (12-20 átomos de carbono) e álcoois de cadeia curta (3-8 átomos de carbono) têm sido largamente utilizados em indústrias de alimentos, detergentes, cosméticos e farmacêuticas [6]. Para estas aplicações, ésteres naturais, tais como aqueles derivados do óleo de baleia, cera de carnaúba e óleo de jojoba têm sido utilizados. No entanto, estes óleos são caros e não estão disponíveis em grandes quantidades. Desta forma, é desejável desenvolver métodos para a produção de tais ésteres a partir de matérias-primas mais baratas e mais largamente disponiveis [10]. 
Métodos químicos convencionais para a produção destes ésteres envolvem sua síntese a partir de um álcool e um ácido carboxílico na presença de um ácido mineral como catalisador. Ácido sulfúrico é comumente utilizado para esta função; infelizmente, ele geralmente leva à formação de subprodutos indesejáveis que podem ser difíceis de serem separados e recuperados do produto [2]. Além disso, neste caso, parte-se de um substrato (ácido graxo) que possui, também, alto valor. Desta forma, surgiu o interesse em realizar a reação de alcoólise, utilizando um óleo vegetal, de baixo custo e de grande produção regional, como matéria-prima, obtendo-se uma mistura de ésteres.

Recentes estudos têm mostrado a possibilidade de uso de um método alternativo para a produção de ésteres pelo uso de enzimas, tais como lipases, como catalisadores [1, 3, 5, 8, 13, 14, 15]. A crescente ênfase no uso de biocatalisadores devido às suas propriedades favoráveis de reação tais como condições amenas e ambientalmente compativeis e sua alta especificidade, tem resultado num aumento do uso de enzimas imobilizadas. Isto vem ocorrendo pois as interações entre o suporte e a enzima podem alterar favoravelmente as propriedades físicas e químicas da enzima e, geralmente, uma nova propriedade é gerada, que pode ser explorada para propostas industriais [4].

O objetivo do presente trabalho é a produção de ésteres etílicos por alcoólise enzimática do óleo de mamona, usando n-hexano como solvente. Uma lipase comercial (Lipozyme IM) foi utilizada como catalisador. Os experimentos foram realizados variando temperatura, concentração de água e enzima no meio reacional e razão molar óleo-etanol, de acordo com um planejamento de experimentos pré-estabelecido. Um modelo empírico foi construído para avaliar a influência das variáveis de processo no rendimento e, desta forma, as condições de operação que maximizam a produção de ésteres foram estabelecidas para a enzima utilizada.

\section{2 - MATERIAL E MÉTODOS}

\section{1 - Materiais}

Óleo de mamona comercial (DELAWARE) foi utilizado sem nenhum tratamento prévio. A composição em ácidos graxos do óleo, determinada por cromatografia gasosa, é de 90\% de ácido ricinoléico e $10 \%$ de outros ácidos. Álcool etílico comercial (95\% de pureza) e n-hexano PA foram utilizados como substrato e solvente, respectivamente.

\section{2 - Enzima}

A lipase comercial utilizada foi gentilmente cedida pela NOVOZYMES Brasil (Araucária-PR): Mucor miehei (Lipozyme IM) imobilizada em resina de troca aniônica $(0,15 \mathrm{U} / \mathrm{g}$ e $4 \%$ de água). A atividade da enzima foi quantificada pelo consumo de ácido láurico na reação de esterificação entre o ácido láurico e o glicerol com razão molar ácido-álcool de 1:3 a temperatura de $60^{\circ} \mathrm{C}$, com a enzima a $5 \%$ (p/p) mantida sob agitação por 40 minutos.
A reação foi iniciada pela adição da Lipozyme IM ao meio reacional, em um reator aberto, de $20 \mathrm{~mL}$, provido de agitação magnética e conectado a um banho termostático. Alíquotas de $150 \mu \mathrm{L}$, em triplicata, foram retiradas do meio reacional no tempo zero e após 40 minutos de reação e foram diluídas em $20 \mathrm{~mL}$ de acetona-etanol (1:1). A quantidade de ácido láurico consumido foi determinada por titulação com $\mathrm{NaOH}$ 0,04N. Uma unidade de atividade foi definida como a quantidade de enzima que conduz ao consumo de $1 \mathrm{mmol}$ de ácido láurico por minuto nas condições experimentais descritas. A quantidade de preparação enzimática e o tempo de reação empregados na determinação da atividade enzimática foram definidos após a obtenção das curvas padrão das reações de esterificação do ácido láurico com o glicerol, na razão estequiométrica a $60^{\circ} \mathrm{C}$, utilizando Lipozyme IM nas concentrações de $1 ; 3 ; 5 ; 7,5$ e $9 \%(\mathrm{p} / \mathrm{p})$ nos tempos de $0 ; 20$; $40 ; 60 ; 80 ; 100 ; 120$ e 140 minutos [12].

\section{3 - Método analítico}

O rendimento do processo foi calculado pela determinação da concentração de glicerol formado durante a reação de alcoólise do óleo vegetal. Sabe-se que o rendimento de glicerol obtido a partir do óleo de mamona, tendo como base sua composição química é de $10 \%$ (p/p) sobre a massa de óleo utilizada [11]. Para comprovar o resultado obtido em glicerol como indiretamente sendo relacionado à conversão em ésteres, foi periodicamente monitorado o teor de ácidos graxos livres no óleo e no produto da reação, verificando não haver variação deste durante o processo e, conseqüentemente, podendo-se concluir que a reação de hidrólise não foi favorecida em nenhuma condição experimental.

O método utilizado para a determinação da concentração de glicerol foi descrito por COCKS \& VAN REDE [7]. O método baseia-se na reação da amostra que contém glicerol com periodato de sódio em solução aquosa para produzir formaldeído e ácido fórmico. Este último é usado como medida de glicerol, pela titulação da amostra com NaOH 0,125N.

\section{4 - Procedimento experimental e análise estatís- tica}

Os experimentos foram realizados em frascos Erlenmeyers de $125 \mathrm{~mL}$, fechados com tampa de vidro. A lipase comercial foi adicionada à mistura óleo-etanol-solvente ( $\mathrm{g}$ de óleo e $40 \mathrm{~mL}$ de $\mathrm{n}$-hexano) e os frascos foram incubados em agitador rotativo a 200rpm por 8 horas, de acordo com o planejamento experimental.

Para determinação das condições experimentais que maximizassem a síntese de ésteres resultantes da reação de alcoólise, foi realizado um planejamento experimental fatorial saturado com 2 níveis e 4 variáveis. As variáveis escolhidas foram temperatura do sistema reacional, concentração de água adicionada ao meio e de enzima e razão molar óleo-etanol. Baseado em estudos realizados preliminarmente, a agitação foi mantida constante, uma vez que foi verificado não haver 
nenhuma alteração no rendimento do processo variando a mesma de 200 a 500rpm [12, 13]. O tempo de reação foi fixado em 8 horas. O intervalo de estudo das variáveis foi determinado de modo a abranger a maioria dos estudos da literatura [8, 12, 13]. Estes valores são fornecidos na Tabela 1.

TABELA 1. Intervalo de estudo das variáveis

$\begin{array}{lc}\text { Variável } & \text { Intervalo de estudo } \\ \text { Temperatura }[\mathrm{T}]\left({ }^{\circ} \mathrm{C}\right) & 35-65 \\ \text { Concentração de água adicionada }[\mathrm{H}]\left(\%(\mathrm{p} / \mathrm{p})^{*}\right) & 0-10 \\ \text { Concentração de enzima }[\mathrm{E}]\left(\%(\mathrm{p} / \mathrm{p})^{*}\right) & 5-20 \\ \text { Razão molar óleo-etanol }[\mathrm{O}: \mathrm{EtOH}] & 1: 3-1: 10\end{array}$

(*) em relação aos substratos (óleo e etanol).

A matriz experimental para o planejamento fatorial é mostrada na Tabela 2. Cabe ressaltar que os experimentos foram realizados randomicamente e com réplica de cada ponto. O erro experimental em cada observação foi obtido através da média e desvio padrão. $O$ uso do planejamento fatorial e a análise estatística permitiram expressar o rendimento do processo como um modelo quadrático, podendo a resposta ser escrita como uma função das variáveis significativas.

TABELA 2. Plano fatorial: condições experimentais

\begin{tabular}{ccccc}
\hline Experimento & $\mathrm{T}\left({ }^{\circ} \mathrm{C}\right)$ & {$[\mathrm{E}] \%(\mathrm{p} / \mathrm{p})$} & {$[\mathrm{H}] \%(\mathrm{p} / \mathrm{p})$} & $\mathrm{O}: \mathrm{EtOH}$ \\
\hline 1 & 35 & 5 & 0 & $1: 3$ \\
2 & 35 & 5 & 10 & $1: 10$ \\
3 & 65 & 20 & 0 & $1: 3$ \\
4 & 65 & 20 & 10 & $1: 10$ \\
5 & 35 & 20 & 10 & $1: 3$ \\
6 & 35 & 20 & 0 & $1: 10$ \\
7 & 65 & 5 & 10 & $1: 3$ \\
8 & 65 & 5 & 0 & $1: 10$ \\
9 & 50 & 12,5 & 5 & $1: 6,5$ \\
\hline
\end{tabular}

\section{5 - Influência das variáveis}

Uma vez determinado o rendimento do processo, um modelo empírico foi construído, com o objetivo de ajustar os dados experimentais e verificar a significância das variáveis, bem como avaliar possiveis interações entre elas. Temperatura, concentração de enzima e de água adicionada ao sistema, razão molar óleo-etanol e interação concentração de água-razão molar óleoetanol foram ajustadas por um modelo quadrático. A estimativa dos parâmetros foi efetuada pelo programa STATISTICA. Os resultados da regressão, bem como o gráfico das conversões experimentais e preditas pelo modelo são apresentadas a seguir. Visando obter uma comparação direta do efeito de cada variável, as variáveis independentes foram normalizadas no intervalo de -1 a +1 , de acordo com a equação 1:

$\mathrm{x}_{\mathrm{i}}=\left[2\left(\mathrm{X}_{\mathrm{i}}-\mathrm{X}_{\text {min }}\right) /\left(\mathrm{X}_{\text {máx }}-\mathrm{X}_{\text {min }}\right)\right]-1$ no qual $x_{i}$ é o valor normalizado da variável $X$ na condição i; $X_{i}$ é o valor real e $X_{\text {min }}$ e $X_{\text {máx }}$ representam o limite inferior e superior, respectivamente. O nivel -1 representa o limite inferior enquanto o nivel +1 representa o limite superior de cada variável.

Uma modelagem estatística foi utilizada visando obter um modelo empírico capaz de reproduzir os dados experimentais. Modelos empíricos foram construídos assumindo que todas as interações entre variáveis eram significativas, estimando os parâmetros relacionados com o efeito das interações e das variáveis e descartando os parâmetros não significativos considerando um nivel de confiança de 95\%. O objetivo na utilização do teste $\mathrm{t}$ de Student é avaliar se os parâmetros são significativamente diferentes de zero. Com relação à análise dos parâmetros, é importante mencionar que um parâmetro com valor negativo implica em um efeito negativo da variável no processo.

Adotando esta metodologia, o efeito das variáveis (temperatura, concentração de água adicionada e de enzima e razão molar óleo-etanol) bem como das interações foi estudado.

\section{3 - RESULTADOS E DISCUSSÃO}

Uma lipase imobilizada comercial foi utilizada como catalisador na reação de alcoólise do óleo de mamona, usando n-hexano como solvente em diferentes condições de operação, objetivando selecionar a condição que fornecesse maior rendimento em ésteres. A escolha da enzima (Lipozyme IM) foi devido a resultados obtidos anteriormente [12, 13], nos quais se demonstrou que esta apresentou melhores resultados para a reação de alcoólise dos óleos de polpa e amêndoa de dendê. Os resultados obtidos no planejamento de experimentos realizados são apresentados na Tabela 3. Os valores são referentes à média de dois experimentos. Baseado nestes valores, o erro experimental foi de, aproximadamente, $10 \%$, mostrando uma boa reprodutibilidade dos experimentos. Os resultados apresentados referem-se aos tempos de reação de 6 e 8 horas.

TABELA 3. Conversões obtidas na alcoólise enzimática do óleo de mamona

\begin{tabular}{ccccccc} 
Experimento & $\begin{array}{c}\mathrm{T} \\
\left({ }^{\circ} \mathrm{C}\right)\end{array}$ & $\begin{array}{c}{[\mathrm{E}]} \\
\%(\mathrm{p} / \mathrm{p})\end{array}$ & $\begin{array}{c}{[\mathrm{H}]} \\
\%(\mathrm{p} / \mathrm{p})\end{array}$ & $\begin{array}{c}\mathrm{O} \text { EtOH } \\
\% \text { Rendimento }\end{array}$ & $\begin{array}{c}\text { \% Rendimento } \\
6 \text { horas }\end{array}$ & 8 horas \\
\hline 1 & 35 & 5 & 0 & $1: 3$ & 55,40 & 68,00 \\
2 & 35 & 5 & 10 & $1: 10$ & 11,14 & 14,00 \\
3 & 65 & 20 & 0 & $1: 3$ & 100,00 & 99,00 \\
4 & 65 & 20 & 10 & $1: 10$ & 100,00 & 100,00 \\
5 & 35 & 20 & 10 & $1: 3$ & 25,60 & 30,60 \\
6 & 35 & 20 & 0 & $1: 10$ & 25,33 & 33,35 \\
7 & 65 & 5 & 10 & $1: 3$ & 87,00 & 99,50 \\
8 & 65 & 5 & 0 & $1: 10$ & 33,70 & 40,00 \\
9 & 50 & 12,5 & 5 & $1: 6,5$ & 99,50 & 90,00
\end{tabular}

De acordo com a Tabela 3 pode-se verificar que conversões de $100 \%$ foram obtidas em diversas condições experimentais para os tempos de 6 e 8 horas. Resulta- 
dos obtidos anteriormente [12, 13] utilizando óleos de polpa e de amêndoa de dendê apontaram rendimentos máximos de 52,30 e 77,45\% em 8 horas de reação, para as condições experimentais 5 e 1, respectivamente. Estes resultados comprovam que a composição química do óleo vegetal utilizado influi diretamente na atividade da lipase. Conforme os resultados obtidos pode-se concluir que, quando o interesse é a produção da mistura de ésteres para a utilização como, por exemplo, em biodiesel, o óleo de mamona oferece maiores rendimentos em comparação aos óleos da polpa e amêndoa de dendê.

Como forma de melhor visualizar os dados experimentais obtidos bem como acompanhar a cinética da reação nas diferentes condições estudadas, amostras de cada experimento foram retiradas de hora em hora e o rendimento determinado em cada ponto. Os dados obtidos são apresentados nas Figuras 1 e 2.

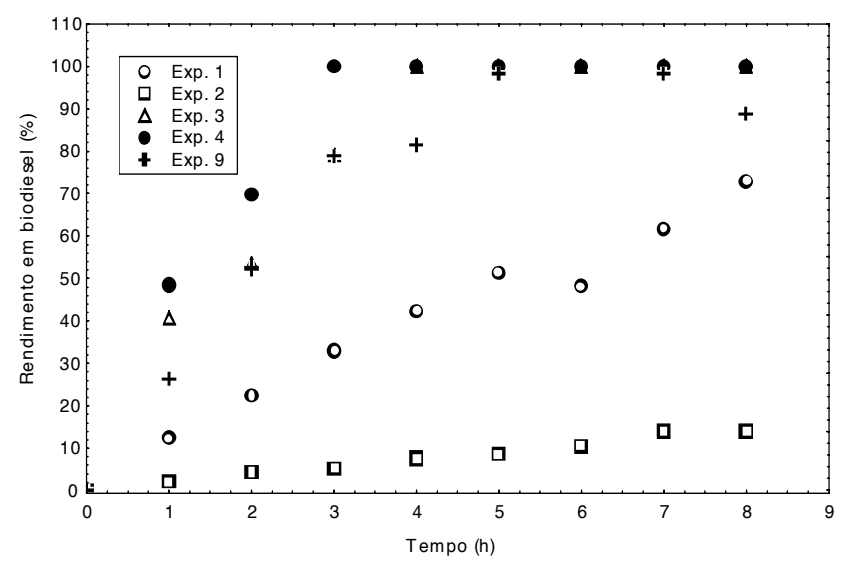

FIGURA 1. Rendimento em ésteres em função do tempo para a alcoólise enzimática do óleo de mamona em n-hexano (Experimentos 1-4 e 9).

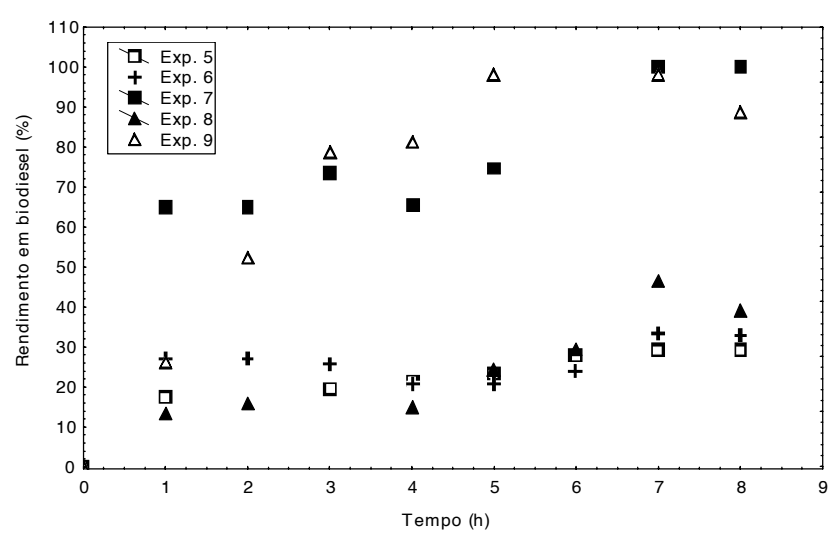

FIGURA 2. Rendimento em ésteres em função do tempo para a alcoólise enzimática do óleo de mamona em n-hexano (Experimentos 5-9).

De acordo com as figuras pode-se verificar que, em um tempo de reação de 6 horas, algumas condições experimentais apontaram um rendimento de 100\%. Além disso, conclui-se, também, que os experimentos realizados utilizando concentração de enzima de $20 \%$ (p/p) conduziram a conversões elevadas. No entanto, conversões similares foram obtidas quando da execução do experimento central, o qual utiliza $12,5 \%$ (p/p) de enzima, apontando para uma condição mais viável uma vez que ocorre uma economia de $7,5 \%(\mathrm{p} / \mathrm{p})$ de enzima. A análise estatística completa a respeito da influência das variáveis de processo no rendimento é apresentada a seguir.

Analisando a Tabela 4 e considerando um nível de confiança de $95 \%$, pode-se observar que a temperatura, a concentração de enzima, a concentração de água, a razão molar óleo-etanol e a interação concentração de água-razão molar óleo-etanol influenciam o rendimento do processo. A temperatura apresentou um efeito negativo, comprovando o fato de que esta enzima apresenta uma maior atividade em torno de $40^{\circ} \mathrm{C}$, sugerindo haver algum tipo de inibição ou inativação em temperaturas mais altas. No que se refere ao efeito da concentração de enzima, esta apresentou um efeito positivo dentro da faixa estudada. Estudos nesse sentido devem ser realizados, principalmente no que se refere à recuperação e reutilização da enzima, tornando mais atrativo o uso de enzimas imobilizadas. A concentração de água apresentou um efeito negativo significativo, apontando para uma provável inativação enzimática devido à água adicionada ou deslocamento do equilíbrio da reação no sentido da reação de hidrólise. Com relação à razão molar óleo-etanol esta também apresentou um efeito significativo, indicando haver inibição da enzima por excesso de substrato (etanol).

TABELA 4. Resultado da regressão para alcoólise enzimática do óleo de mamona em n-hexano

\begin{tabular}{|c|c|c|c|c|c|c|c|}
\hline \multicolumn{8}{|c|}{ Modelo: $Y=A_{0}+A_{1}{ }^{*} T+A_{2}{ }^{*} E+A_{3}{ }^{*} H+A_{4}{ }^{*} R+A_{5}{ }^{*} T^{*} T+A_{6}{ }^{*} H^{*} R$} \\
\hline & $A_{0}$ & $A_{1}$ & $\mathrm{~A}_{2}$ & $\mathrm{~A}_{3}$ & $\mathrm{~A}_{4}$ & $A_{5}$ & $A_{6}$ \\
\hline $\begin{array}{l}\text { Parâmetro } \\
\text { estimado }\end{array}$ & 99,49998 & $-11,8638$ & 25,40376 & $-12,2288$ & $-12,1613$ & $-44,7287$ & $-7,96125$ \\
\hline $\begin{array}{l}\text { Desvio } \\
\text { padrão }\end{array}$ & 3,19755 & 1,1305 & 1,13050 & 1,1305 & 1,1305 & 3,3915 & 1,13050 \\
\hline
\end{tabular}

A Figura 3 apresenta a comparação entre os dados experimentais e gerados pelo modelo empírico, onde pode se observar uma boa concordância entre eles, corroborando o modelo proposto.

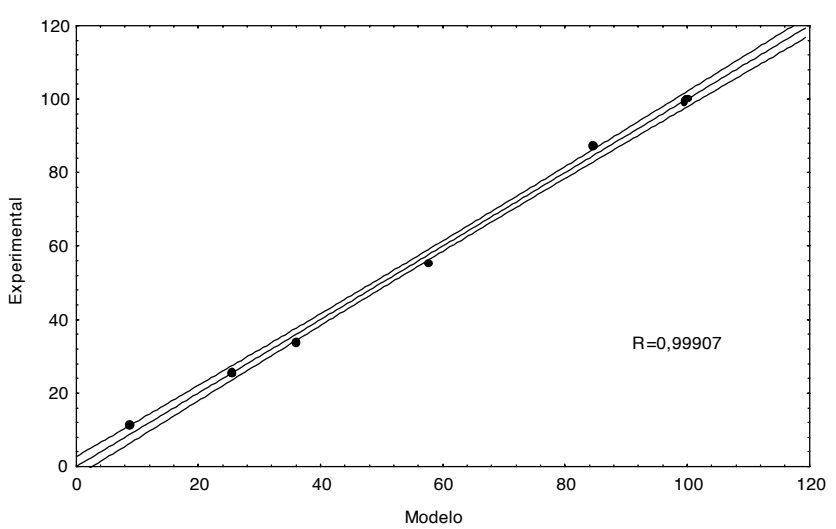

FIGURA 3. Rendimento experimental e predito para o óleo de mamona em n-hexano. 
Os resultados obtidos neste trabalho corroboram os obtidos por OLIVEIRA \& ALVES [13], no qual verificou-se a necessidade de avaliação da influência das variáveis do processo cada vez que um novo sistema (óleo vegetal) é estudado. Tal fato comprova que a composição química do óleo influi diretamente na atividade da enzima utilizada no processo.

\section{4 - CONCLUSÕES}

O emprego do planejamento de experimentos na otimização do rendimento do processo de alcoólise de óleos vegetais, usando lipases imobilizadas como catalisadores, se mostrou eficiente no estudo da influência das variáveis do processo. Um modelo empírico foi estabelecido, mostrando boa concordância com os dados experimentais obtidos. Os efeitos das variáveis puderam ser avaliados e foi realizada uma análise aprofundada da influência das mesmas no rendimento. De acordo com o estudo realizado neste trabalho, verificou-se que conversões de $100 \%$ em ésteres foram obtidas para várias condições experimentais, apontando a potencialidade de utilização do óleo de mamona na produção de tais compostos. Além disso, a comparação com os dados obtidos anteriormente [12, 13] salienta a importância em se realizar este estudo cada vez que o sistema (substrato e enzima) for modificado.

\section{5 - REFERÊNCIAS BIBLIOGRÁFICAS}

[1] ABRAMOWICZ, D.A.; KEESE, C.R. Enzymatic transesterification of carbonates in water restrictes environments. Biotechnology and Bioengineering., v. 33, p. 149-156, 1989.

[2] AL SAADI, A.N.; JEFFREYS, G.V. Esterification of butanol in a two phase liquid-liquid system. AIChE Journal, v. 27, p. 754-772, 1981.

[3] BARZANO, E.; KAREL, M.; KLIBANOV, A.M. Enzymatic oxidation of ethanol in the gaseous phase. Biotechnology and Bioengineering, v. 34, p. 1178$1185,1989$.
[4] BASRI, M.; AMPON, W.M.Z.; RAZAK, C.N.A.; SALLEH, A.B. Enzymatic synthesis of fatty esters by hydrophobic lipase derivatives immobilized on organic polymer beds. Journal of the American Oil Chemists' Society, v. 72, p. 407-411, 1995.

[5] BRUNT, J.V. Coaxing enzymes to act in organic solvents. Biotechnology, v. 4, p. 611, 1986.

[6] CARTA, G.; GAINER, J.L.; ZAIDI, A. Fatty acid esterification using nylon immobilized lipase. Biotechnology and Bioengineering, v. 48, p. 601-605, 1995.

[7] COKS, L.V.; VAN REDE, C. Laboratory handbook for oils and fats analysis. Acad. Press, p. 196, Londres, 1966.

[8] DORDICK, J. S., Enzymatic catalysis in monophasic organic solvents. Enzyme Microbial Technology, v. 11, p. 194-211, 1989.

[9] MALCATA, F.X.; REYES, H.R.; GARCIA, H.S.; HILL, C.G.; AMUNDSON, C.H. Immobilized lipase reactors for modification of fats and oils Journal of the American Oil Chemists' Society, v. 67, p. 890-910, 1990.

[10] MARTINEZ, M.; TORRANO, E.; ARACIL, J. An analogue of jojoba oil. A statistical approach. Industrial \& Engineering Chemistry Research, v. 27, p. 2179-2182, 1988.

[11] MONACO, L.C. Produção de combustíveis líquidos a partir de óleos vegetais, MIC/STI, p. 277, Brasília, 1985.

[12] OLIVEIRA, D.; ALVES, T.L. Enzymatic alcoholysis of palm and palm kernel oil. Applied Biochemistry and Biotechnology, v. 77-79, p. 835-844, 1999.

[13] OLIVEIRA, D.; ALVES, T.L. A kinetic study of lipasecatalyzed alcoholysis of palm kernel oil. Applied Biochemistry and Biotechnology, v. 84-86, p. 59-68, 2000.

[14] STEVEnSON, D.E.; STORER, A.C. Papain in organic solvents: Determination of conditions suitable for biocatalysis and the effect on substrate specificity and inhibition. Biotechnology and Bioengineering, v. 37,p. 519-527, 1991.

[15] YAMANE, T. Importance of moisture content control for enzymatic reactions in organic solvents: A novel concept of microaqueous biocatalysis. Biocatalysis., v. 2, p. 1-9, 1988. 